\title{
RBGG: Muito além do Rio de Janeiro
}

\section{BGG Far begondRiodeJaniro}

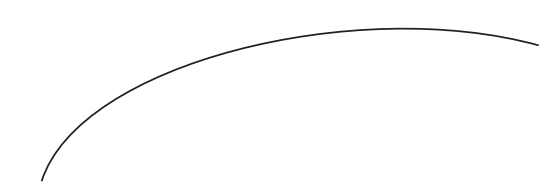

A Revista Brasileira de Geriatria e Gerontologia (Brazilian Journal of Geriatrics and Gerontology) tem-se configurado como um periódico com grande abrangência nacional, e também como veículo de divulgação de artigos originários do exterior.

Neste número são publicados 17 artigos originais e um artigo de revisão. Ao apreciarmos suas origens, identificamos que seis são provenientes da Região Nordeste do Brasil (estados de Pernambuco, Maranhão, Bahia e Ceará); seis artigos vêm da Região Sul (Rio Grande do Sul e Paraná); três são do estado de São Paulo; um do Mato Grosso e um do Distrito Federal. Há também um artigo proveniente da França. Curiosamente, neste número não há sequer um artigo do estado onde está sediada a RBGG: o Rio de Janeiro.

A publicação dos manuscritos submetidos obedece a critérios que envolvem a ordem de chegada, a avaliação editorial inicial, o envio e a recepção dos pareceres dos revisores, até a decisão editorial final para publicação. Além disso, o fato de este número apresentar artigos com origens tão diversas se deve a uma preocupação com a abrangência da produção nacional.

A Revista Brasileira de Geriatria e Gerontologia ultrapassa fronteiras geográficas e, hoje, é um dos principais veículos de divulgação do conhecimento científico no campo do envelhecimento. Assim, é com orgulho que apresentamos mais este número - o terceiro de 2012. 